\title{
Pengetahuan, Persepsi dan Sikap Tentang Obat pada Siswa SMK Muhammadiyah Susukan Kabupaten Semarang
}

\author{
Fitria Nugrahaeni ${ }^{1 *}$, Miatin Rachmawati ${ }^{2}$ \\ ${ }^{1}$ Fakultas Farmasi, Universitas Muhammadiyah Prof. Dr. HAMKA, Jakarta, Indonesia \\ ${ }^{2}$ Fakultas Agama Islam, Universitas Muhammadiyah Prof. Dr. HAMKA, Jakarta, Indonesia \\ *Corresponding Author. E-mail: fitria.nugrahaeni@uhamka.ac.id
}

\begin{abstract}
Irrational use of drug and drug abuse are some of the impacts of the low knowledge of the public about medicine, including vocational students. This study aimed to assess the knowledge, perceptions, and attitudes of Muhammadiyah Susukan high school (SMK) students about medicine. The research was conducted by using descriptive and analytical methods with cross sectional using a questionnaire instrument. This research was conducted in June 2020. Data were analyzed using univariate and bivariate analysis. The results obtained indicate that student's perceptions of drug safety are $76.7 \%$, students have a positive behavior with drugs $91.7 \%$, but have less knowledge (50.6\%). The place where respondents live in the village has a close relationship with their level of the knowledge. There is a relationship between perception and attitude $(P<0.05)$ but there is no relationship between knowledge and perception $(P>0.05)$, and between knowledge and attitude $(P>0.05)$. Low levels of knowledge and perceptions can cause students to abuse drugs or use drugs that are not rational. So that efforts are needed to increase students'knowledge about medicine.
\end{abstract}

Keywords: knowledge, perceptions, attitudes about medicine, students

\section{ABSTRAK}

Penggunaan obat yang tidak rasional adalah salah satu dampak dari rendahnya pengetahuan masyarakat tentang obat, termasuk siswa sekolah menengah kejuruan. Penelitian ini bertujuan untuk menilai pengetahuan, persepsi, dan sikap siswa sekolah menengah kejuruan (SMK) Muhammadiyah Susukan tentang obat-obatan. Penelitian dilakukan dengan metode deksriptif dan analitik secara cross sectional menggunakan instrumen kuesioner. Penelitian ini dilakukan pada bulan Juni 2020. Data dianalisis menggunakan analisis univariat dan bivariat. Hasil yang didapatkan menunjukkan bahwa persepsi siswa terhadap keamanan obat dengan kategori tinggi $76,7 \%$, pada sikap positif siswa terhadap obat sebanyak $91,7 \%$, tetapi mempunyai pengetahuan yang kurang (56\%). Kediaman responden yang tinggal di desa memiliki hubungan erat dengan tingkat pengetahuan. Ada hubungan antara persepsi dan sikap $(\mathrm{P}<0,05)$ tetapi tidak ada hubungan antara pengetahuan dan persepsi $(\mathrm{P}>0,05)$, serta antara pengetahuan dan sikap $(\mathrm{P}>0,05)$. Tingkat pengetahuan yang rendah dan persepsi dapat menyebabkan siswa melakukan penyalahgunaan obat atau penggunaan obat yang tidak rasional. Sehingga diperlukan upaya untuk meningkatkan pengetahuan siswa tentang obat.

Kata Kunci: pengetahuan, persepsi, sikap tentang obat, siswa

Submitted: December $18^{\text {th }} 2020 \mid$ Accepted: November $18^{\text {th }} 2021 \mid$ Published: December $31^{\text {st }} 2021$

\section{Pendahuluan}

Sebagian besar intervensi medik obat dan biaya obat merupakan biaya terbesar yaitu sekitar $60-70 \%$ dari total biaya pengobatan [1]. Dimensi obat luas sehingga dalam mengonsumsinya sangat berdampak langsung kepada derajat kesehatan masyarakat termasuk pada kelompok usia remaja. Apalagi remaja rentan terhadap masalah yang ditimbulkan akibat penggunaan obat [2].

Prevalensi peresepan obat pada anak-anak dan remaja secara internasional dilaporan bervariasi 51\%$70 \%$. Penggunaan yang relatif tinggi dilaporkan terjadi pada penggunaan obat obat bebas dan bebas terbatas yang disebut dengan istilah over the counter (OTC) [3].
Remaja umumnya sudah akrab dengan penyakit dan pengobatannya, sehingga mereka sebenarnya dapat berperan aktif dalam penggunaan obat [4]. Namun, pengetahuan mereka terkait obat cukup terbatas sehingga dapat terjadi salah penggunaan, serta takut dalam penggunaan obat-obatan [5] [6]

Penggunaan obat bebas dan bebas terbatas dalam swamedikasi meningkat pada negara maju dan berkembang. Sekitar 50\% anak di Finlandia dan Ethiopia telah melakukan praktik swamedikasi dan $17 \%$ diantaranya menggunakan OTC [7]. Masa remaja adalah masa yang sangat penting karena sebagian besar praktik swamedikasi biasanya dimulai pada masa ini. Selain itu, masa ini merupakan masa belajar di sekolah menengah. 
Penggunaan obat yang tidak rasional akan memberikan efek negatif yang besar baik secara klinik maupun ekonomi [8]. Masalah yang mengkhawatirkan adalah terkait penggunaan antibiotik yang tidak rasional. Hal ini akan memberi andil yang sangat besar terhadap terjadinya resistensi antibiotik [9]. Selain itu, penyalahgunaan obatobat yang dijual bebas di minimarket dan apotek akan memberikan andil yang sangat besar demi kemajuan generasi penerus bangsa. Berdasarkan hal tersebut, maka perlu dilakukan penelitian untuk mengetahui tingkat pengetahuan, persepsi dan sikap siswa SMK terhadap penggunaan obat.

\section{Metode Penelitian}

\section{Rancangan Penelitian}

Penelitian ini termasuk jenis penelitian deksriptif, analitik dengan pendekatan cross sectional. Metode pangambilan sampel yang digunakan adalah random sampling dengan teknik pengambilan sampel yaitu proporsional random sampling.

Penentuan besarnya sampel dilakukan menggunakan rumus slovin, dengan jumlah sampel yang diambil sebanyak 150 siswa. Instrumen yang digunakan adalah kuesioner yang diadopsi dari penelitian sebelumnya karena cukup sederhana dan mudah dimengerti. Kuesioner memiliki 16 pertanyaan yang dibagi menjadi tiga kategori yaitu persepsi siswa terhadap efek berbahaya dari obat-obatan, pengetahuan tentang hubungan antara efikasi obat dengan formulasi, dan sikap siswa terhadap tenaga kesehatan. Kuesioner ini diterjemahkan ke dalam Bahasa Indonesia sesuai prosedur, kemudian dilakukan uji reliabilitas dan validitas kepada 30 orang responden dengan parameter penerimaan melalui uji korelasi Pearson Product Moment dan Cronbach's Alpha.

\section{Analisis Data}

Analisis data yang dilakukan berupa analisis univariat dan bivariat. Pada variabel persepsi, dikategorikan jika jawaban benar responden $>60 \%$ atau $>2$ dari 5 pertanyaan, persepsi rendah jika jawaban benar responden $<60 \%$ atau $<3$ dari 5 pertanyaan. Variabel pengetahuan dikategorikan baik jika jawaban benar responden $>60 \%$ atau $>2$ dari 4 pertanyaan, pengetahuan kurang jika jawaban benar responden
$<60 \%$ atau $<3$ dari 4 pertanyaan. Sedangkan varibel sikap dikategorikan positif jika nilai $\mathrm{T}>\mathrm{T}$ rata-rata $(50,1)$ dan negatif jika $\mathrm{T}<$ rata-rata $(50,1)$. Analisis bivariat menggunakan Chisquare test dengan bantuan program SPSS versi 23.

\section{Hasil dan Pembahasan}

\section{Data Karakteristik Responden}

Instrumen kuesioner yang dipakai diuji rehabilitas dan validitasnya kepada 30 responden dengan kriteria yang sama dengan sampel yang akan dipilih dalam penelitian. Berdasarkan analisis statistik terhadap data yang diperoleh, semua item pertanyaan valid dan reliabel dengan nilai pearson correlation $>0,451$ dan alpha Cronbach's $>0,6$.

Dari hasil analisis data seperti yang disajikan dalam Tabel 1, diperoleh karakteristik responden yaitu umumnya responden berumur 16 tahun $(38,3 \%)$ dengan jenis kelamin perempuan $80,9 \%$ dan laki-laki 19,1\%. Responden tertinggi pada kelas XII $(53,2 \%)$ dengan proporsi jurusan tata busana sebanyak $80,9 \%$. Umumnya responden tinggal di desa $(82,7 \%)$. dan tidak ada responden yang memiliki keluarga bekerja di bidang kesehatan.

\section{Data Persepsi Responden}

Gambaran persepsi responden tentang efek berbahaya dari obat memberikan hasil yang cukup menarik. Sekitar 47,3\% responden menyatakan bahwa obat-obatan tidak berbahaya bagi kesehatan. Hal ini mengkhawatirkan karena persepsi yang keliru seperti ini dapat menjerumuskan siswa untuk menggunakan obat secara tidak tepat. Hasil yang berbeda ditunjukkan oleh siswa SMP di Ethiopia, 74,2\% setuju dengan pernyataan kehati-hatian terhadap bahaya dari obat OTC dan hampir $75 \%$ memiliki pengetahuan yang baik tentang bahaya obat [12]. Sedangkan persepsi yang lain memberikan gambaran yang sangat baik dengan presentase 82,7\% - 91,3\% (Tabel 2).

\section{Data Pengetahuan Responden}

Gambaran pengetahuan responden tentang pengaruh formulasi terhadap efektifitas obat memberikan hasil yang rendah untuk semua item pertanyaan dimana hanya 36\%$50,7 \%$ responden yang menjawab benar. Mereka berpendapat bahwa rasa, ukuran, bentuk dan warna sediaan memengaruhi

Tabel 1. Karakteristik responden

\begin{tabular}{|c|c|c|c|}
\hline Karakteristik & Parameter & Jumlah & Proporsi (\%) \\
\hline \multirow{5}{*}{ Usia } & 15 tahun & 13 & 8,5 \\
\hline & 16 tahun & 57 & 38,3 \\
\hline & 17 tahun & 54 & 36,2 \\
\hline & 18 tahun & 16 & 10,6 \\
\hline & 19 tahun & 10 & 6,4 \\
\hline \multirow{2}{*}{ Jenis Kelamin } & Laki-laki & 29 & 19,1 \\
\hline & Perempuan & 121 & 80,9 \\
\hline \multirow{2}{*}{ Kelas } & XI & 70 & 46,8 \\
\hline & XII & 80 & 53,2 \\
\hline \multirow{2}{*}{ Jurusan } & Teknik Kendaraan Ringan & 29 & 19,1 \\
\hline & Tata Busana & 121 & 80,9 \\
\hline \multirow{2}{*}{ Alamat Rumah } & Kota & 26 & 17,3 \\
\hline & Desa & 124 & 82,7 \\
\hline \multirow{2}{*}{ Keluarga bekerja di bidang kesehatan } & Ada & 0 & 0 \\
\hline & Tidak ada & 150 & 100 \\
\hline
\end{tabular}


efektivitas obat. Hasil yang sama juga diperoleh oleh A.S. Eldalo [13]. Pengetahuan yang salah seperti ini mungkin disebabkan oleh masih rendahnya pemahaman responden terhadap obat. Hal yang sama juga ditemukan pada remaja 1520 tahun di Saudi Arabia, hanya 15,4\% dari responden yang mengetahui penggunaan obat yang benar [14]. Pengetahuan tentang obat yang cukup tinggi ditunjukkan oleh remaja di Malta, namun persepsi mereka tentang penggunaan obat menunjukkan hal yang sama dengan peneltian ini [15].

\section{Data Aspek Sikap Responden}

Aspek sikap, secara keseluruhan juga memberikan hasil yang positif dengan jumlah responden yang menjawab benar di atas 90\% responden, kecuali untuk item pentingnya

Tabel 2. Gambaran Persepsi Responden

\begin{tabular}{lcc}
\hline \multicolumn{1}{c}{ Pertanyaan } & \multicolumn{2}{c}{ Jawaban Benar } \\
\cline { 2 - 3 } & $\mathbf{N}$ & $\mathbf{\%}$ \\
\hline $\begin{array}{l}\text { Apakah obat-obatan berbahaya bagi } \\
\text { manusia? }\end{array}$ & 79 & 52,7 \\
$\begin{array}{l}\text { Menurut anda apakah beberapa obat } \\
\text { dapat menyebabkan alergi? }\end{array}$ & 124 & 82,7 \\
$\begin{array}{l}\text { Apakah obat yang sama dapat } \\
\text { digunakan dewasa dan anak-anak ? }\end{array}$ & 137 & 91,3 \\
$\begin{array}{l}\text { Apakah anak-anak dapat } \\
\text { menggunakan obat tanpa } \\
\text { konsultasi? }\end{array}$ & 135 & 90 \\
\hline
\end{tabular}

menceritakan riwayat obat ke dokter yaitu 84\% (Tabel 4). Hasil yang mirip juga ditunjukkan pada penelitian A.S. Eldalo [16].

Berdasarkan hasil kategorisasi variabel, diperoleh hasil bahwa persepsi siswa terhadap keamanan obat dikategorikan tinggi $(76,7 \%)$, siswa bersikap positif terhadap obat $(91,7 \%)$ namun memiliki pengetahuan yang kurang (56\%) (Tabel 5).

Hasil uji bivariat antara karakteristik dengan tingkat persepsi, pengetahuan dan sikap menunjukan tidak adanya hubungan yang bermakna antar variabel, kecuali alamat tinggal (kota atau desa) dengan pengetahuan (Tabel 6).

Responden yang tinggal di kota memiliki pengetahuan yang berbeda secara bermakna dengan yang tinggal di desa $(\mathrm{P}<0,05)$, dimana responden yang tinggal di kota memiliki

Tabel 3. Gambaran Pengetahuan Responden

\begin{tabular}{llc}
\hline \multicolumn{1}{c}{ Pertanyaan } & \multicolumn{2}{c}{ Jawaban Benar } \\
\cline { 2 - 3 } & $\mathbf{N}$ & \% \\
\hline $\begin{array}{l}\text { Apakah rasa obat } \\
\text { memengaruhi efektivitasnya? }\end{array}$ & 54 & 36,0 \\
$\begin{array}{l}\text { Apakah ukuran tablet akan } \\
\text { memengaruhi efektivitasnya? }\end{array}$ & 65 & 43,3 \\
$\begin{array}{l}\text { Apakah bentuk sediaan } \\
\text { memengaruhi efektivitasnya? }\end{array}$ & 69 & 46,0 \\
$\begin{array}{l}\text { Apakah warna obat } \\
\text { memengaruhi efektivitasnya? }\end{array}$ & 76 & 50,7 \\
\hline
\end{tabular}

Tabel 4. Gambaran sikap responden

\begin{tabular}{llc}
\hline \multicolumn{1}{c}{ Pertanyaan } & Jawaban Benar \\
\cline { 2 - 2 } $\begin{array}{l}\text { Jika anda mendapat obat baru, apakah penting untuk bertanya tentang } \\
\text { khasiatnya? }\end{array}$ & $\mathbf{N}$ \\
$\begin{array}{l}\text { Jika anda mendapat obat baru, apakah penting untuk bertanya lama } \\
\text { pemakaiannya? }\end{array}$ & 147 \\
$\begin{array}{l}\text { Jika anda mendapat obat baru, apakah bertanya kapan dan bagaimana cara } \\
\text { menggunakannya? }\end{array}$ & 134 \\
$\begin{array}{l}\text { Jika anda mendapat obat baru, apakah bertanya efek sampingnya? } \\
\text { Apakah anda menceritakan kepada dokter tentang riwayat obat yang sudah } \\
\text { digunakan? }\end{array}$ & 136 \\
$\begin{array}{l}\text { Apakah anda menceritakan kepada dokter tentang alergi obat yang dimiliki? } \\
\text { Menurut anda apakah penting bagi wanita hamil untuk berkonsultsi dengan } \\
\text { dokter sebelum mengonsumsi obat? }\end{array}$ & 126 \\
\hline
\end{tabular}

Tabel 5. Tingkat persepsi, pengetahuan, dan sikap responden

\begin{tabular}{lcc}
\hline \multicolumn{1}{c}{ Nama Variabel } & Parameter & Proporsi \\
\hline \multirow{2}{*}{ Persepsi } & Tinggi & 76,7 \\
& Rendah & 23,3 \\
\hline \multirow{2}{*}{ Pengetahuan } & Baik & 44 \\
& Kurang & 56 \\
\hline \multirow{2}{*}{ Sikap } & Positif & 91,7 \\
& Negatif & 8,3 \\
\hline
\end{tabular}

Tabel 6. Hubungan karakteristik dengan variabel

\begin{tabular}{lccc}
\hline Karakteristik & \multicolumn{3}{c}{ Sig } \\
\cline { 2 - 4 } & Persepsi & Pengetahuan & Sikap \\
\hline Jenis Kelamin & 0,146 & 0,819 & 0,213 \\
Kelas & 0,670 & 0,593 & 0,176 \\
Jurusan & 0,970 & 0,336 & 0,296 \\
Alamat rumah & 0,733 & $0,003^{*}$ & 0,467 \\
$\begin{array}{l}\text { Keluarga yang } \\
\text { bekerja di } \\
\text { kesehatan }\end{array}$ & 0,967 & 0,696 & 0,976 \\
\hline
\end{tabular}


pengetahuan yang lebih tinggi daripada yang tinggal didesa. Selanjutnya, tabulasi silang antara ketiga variabel yaitu persepsi dengan pengetahuan, persepsi dengan sikap dan pengetahuan dengan sikap menggunakan uji Chisquare diperoleh signifikansi 0,564 yang tidak berbeda $(\mathrm{P}>0,05)$.

Dari hasil di atas terlihat bahwa pentingnya edukasi pendidikan mengenai obat kepada siswa di sekolah, karena siswa merupakan kelompok yang potensial menggunakan obat terutama OTC untuk swamedikasi. Penelitian di Mafraq, Jordania, memunjukkan bahwa b7\% siswa SD dan SMP di sana telah pernah menggunakan OTC . Penelitian yang sama di Jakarta pada siswa SMA sekitar 80\% responden melakukan praktik swamedikasi terutama saat ujian.

\section{Kesimpulan}

Persepsi siswa terhadap keamanan obat dikategorikan tinggi $(76,7 \%)$, siswa bersikap positif terhadap obat $(91,7 \%)$ namun memiliki pengetahuan yang kurang $(56 \%)$. Kediaman responden yang tinggal di kota atau desa memiliki perbedaan bermakna dengan tingkat pengetahuan. Siswa yang tinggal di kota memiliki pengetahuan yang lebih tinggi dibandingkan dengan siswa yang tinggal di desa. Terdapat hubungan antara persepsi dengan sikap $(\mathrm{P}<0,05)$, namun tidak ada hubungan antara pengetahuan dengan tingkat persepsi $(\mathrm{P}>0,05)$ dan antara pengetahuan dengan sikap $(\mathrm{P}>0,05)$. Oleh sebab itu, perlu diberikan pendidikan obat kepada siswa sejak dini terutama untuk siswa SMK.

\section{Ucapan Terimakasih}

Terimakasih kepada Lembaga Penelitian dan Pengembangan Universitas Muhammadiyah Prof DR. HAMKA yang telah mendanai penelitian ini.

\section{Daftar Pustaka}

[1] Rajiah, Kingston, Mari Kannan Maharajan, and Shashina Nair. 2016. "Pharmacy Students' Knowledge and Perceptions about Adverse Drug Reactions Reporting and Pharmacovigilance." Saudi Pharmaceutical Journal 24(5):600-604.

[2] Nisa, Zaka Un, Ayesha Zafar, and Farooq Sher. 2018. "Assessment of Knowledge, Attitude and Practice of Adverse Drug Reaction Reporting among Healthcare Professionals in Secondary and Tertiary Hospitals in the Capital of Pakistan." Saudi Pharmaceutical Journal 26(4):453-61.

[3] Liu, Xiao, and Hsinchun Chen. 2015. "A Research Framework for Pharmacovigilance in Health Social Media: Identification and Evaluation of Patient Adverse Drug Event Reports." Journal of Biomedical Informatics 58:268-79.

[4] Shafaiyaz M, and Yamuna devi M.S. 2019. "Knowledge, Attitude, Awareness on Rational Use of Drugs Among the Para - Medical Students in a Tertiary Care Hospital - a Questionnaire Based Study." International Journal of Advanced Research 7(10):1209-15.

[5 ] Herawati, Lucky, Johan Arief Budiman, and Haryono. 2018. “Adolescent's Knowledge and Skill to Refuse Drugs.” Kesmas 13(1):48-52.

[6] Kumar, Chiranjeevi Uday, G. Harijagannadha Rao, and G. Vasavi. 2019. "A Questionnaire Based Study on the Knowledge, Attitude and the Practices of Pharmacovigilance among the
Postgraduate Students at a Tertiary Care Hospital in South India.” International Journal of Basic \& Clinical Pharmacology 8(3):457.

[7] P, Divya Sree, Dhivya K, Lakshmi Prasanna S, Gnana Chaitanya C, and Nazma M. 2017. "Evaluation of Knowledge, Attitude and Practice Towards Drug Use Along With Good Pharmacy Practice Among Pharmacy Students of Sri Venkateswara College, Chittoor, India." International Research Journal of Pharmacy 8(3):29-32.

[8] Eldalo,Ahmed S., MirghaniA. Yousif, and MustafaAwadAbdallah. 2014. "Saudi School Students' Knowledge, Attitude and Practice toward Medicines." Saudi Pharmaceutical Journal 22(3):213-18.

[9] Fatokun, Omotayo, Mohamed Azmi Hassali, Mohamed Izham, and Mohamed Ibrahim. 2011. "Generic Competition and Drug Prices in the Malaysian Off-Patent Pharmaceutical Market Spinal Rehabilitation View Project Patient Safety View Project Generic Competition and Drug Prices in the Malaysian off-Patent Pharmaceutical Market." Article in Journal of Applied Pharmaceutical Science.

[10] Azmi Hassali, Mohamed, Asrul Akmal Shafie, Fahad Saleem, Noman ul Haq, Ginnie Chua, Chee Ping Chong, Muhammad Atif, and Noman Ul Haq. n.d. "Community Pharmacist's Perceptions towards the Quality of Locally Manufactured Generic Medicines: A Descriptive Study from Malaysia."

[11] Generali, Joyce A. 2014. "Adverse Drug Event Reporting: Awareness Is Not Enough." Hospital Pharmacy 49(2):110-11.

[12] Iyeke, Patrick, and Onoharigho Festus Dafe. 2016. "Knowledge of Hazards of Self-Medication among Secondary School Students in Ethiopia East Local Government Area of Delta State." Journal of Education and Practice 7(5):105-15.

[13] Palmer, Rebekka S., Thomas J. Mcmahon, Danielle I. Moreggi, Bruce J. Rounsaville, and Samuel A. Ball. 2012. "College Student Drug Use: Patterns, Concerns, Consequences, and Interest in Intervention." Journal of College Student Development 53(1):124-32.

[14] Syofyan, Syofyan, Habibie Deswilyaz Ghiffari, and Erizal Zaini. 2017. "Persepsi, Pengetahuan, Dan Sikap Tentang Obat Pada Siswa Sekolah Menengah Atas (SMA) Di Kota Pariaman, Sumatera Barat." Jurnal Sains Farmasi \& Klinis 4(1):83.

[15] Latifi, Arman, Ali Ramezankhani, Zahed Rezaei, Hossein Ashtarian, Behnam Salmani, Mohammad Reza Yousefi, and Mehdi Khezeli. 2017. "Prevalence and Associated Factors of Self-Medication among the College Students in Tehran." Journal of Applied Pharmaceutical Science 7(7):128-32.

[16] Klemenc-Ketis, Zalika, Ziga Hladnik, and Janko Kersnik. 2010. "Self-Medication among Healthcare and Non-Healthcare Students at University of Ljubljana, Slovenia." Medical Principles and Practice 19(5):395-401.

[17] Rahmawati,FitriNugrahaeni\&.Miatin.2019."TingkatPengetahun Terhadap Perilaku Swamedikasi BatukPada SMAMuhammadiyah Jakarta." Social Clinic Pharmacy Indonesia Jurnal 4(2):54-65 